\title{
Sixteen Weeks of Supplementation with a Nutritional Quantity of a Diversity of Polyphenols from Foodstuff Extracts Improves the Health-Related Quality of Life of Overweight and Obese Volunteers: A Randomized, Double-Blind, Parallel Clinical Trial
}

\author{
Cindy Romain ${ }^{1} \mathbb{D}$, Linda H. Chung ${ }^{2} \mathbb{D}$, Elena Marín-Cascales ${ }^{2}\left(\mathbb{D}\right.$, Jacobo A. Rubio-Arias ${ }^{2}$ (D), Sylvie Gaillet ${ }^{3}$, \\ Caroline Laurent ${ }^{3}$, Juana María Morillas-Ruiz ${ }^{4}$, Alejandro Martínez-Rodriguez ${ }^{2}$, Pedro Emilio Alcaraz ${ }^{2}$ (D) \\ and Julien Cases ${ }^{1, *(D)}$
}

\section{check for}

updates

Citation: Romain, C.; Chung, L.H.; Marín-Cascales, E.; Rubio-Arias, J.A.; Gaillet, S.; Laurent, C.; Morillas-Ruiz, J.M.; Martínez-Rodriguez, A.;

Alcaraz, P.E.; Cases, J. Sixteen Weeks of Supplementation with a

Nutritional Quantity of a Diversity of Polyphenols from Foodstuff Extracts Improves the Health-Related Quality of Life of Overweight and Obese

Volunteers: A Randomized, Double-Blind, Parallel Clinical Trial. Nutrients 2021, 13, 492. https:// doi.org/10.3390/nu13020492

Academic Editors:

Elena González-Burgo and Emad Al-Dujaili

Received: 14 December 2020

Accepted: 28 January 2021

Published: 2 February 2021

Publisher's Note: MDPI stays neutral with regard to jurisdictional claims in published maps and institutional affiliations.

Copyright: (c) 2021 by the authors. Licensee MDPI, Basel, Switzerland. This article is an open access article distributed under the terms and conditions of the Creative Commons Attribution (CC BY) license (https:/ / creativecommons.org/licenses/by/ $4.0 /)$.
1 Innovation and Scientific Affairs, Fytexia, 34350 Vendres, France; cromain@fytexia.com

2 Research Center for High Performance Sport, Catholic University of Murcia, 30107 Murcia, Spain; lhchung@ucam.edu (L.H.C.); emarin@ucam.edu (E.M.-C.); jararias@ucam.edu (J.A.R.-A.); amrodriguez@ucam.edu (A.M.-R.); palcaraz@ucam.edu (P.E.A.)

3 UMR 204 Nutripass, Research Institute for Development, University of Montpellier, 34095 Montpellier, France; sylvie.gaillet-foulon@univ-montp2.fr (S.G.); caroline.laurent@univ-montp2.fr (C.L.)

4 Department of Food and Nutrition Technology, Catholic University of Murcia, 30107 Murcia, Spain; jmmorillas@ucam.edu

* Correspondence: jcases@fytexia.com; Tel.: +33-467-219-098

\begin{abstract}
Overweight and obesity adversely affect health-related quality of life (HRQOL) through day-to-day impairments of both mental and physical functioning. It is assumed that polyphenols within the Mediterranean diet may contribute to improving HRQOL. This investigation aimed at studying the effects of a polyphenol-rich ingredient on HRQOL in overweight and obese but otherwise healthy individuals. A randomized, double-blind, placebo-controlled study including 72 volunteers was conducted. Subjects were randomly assigned to receive for a 16-week period either $900 \mathrm{mg}$ / day of the supplement or a placebo. Dietary recommendations were individually determined and intakes were recorded. Daily physical mobility was also monitored. Improvement of HRQOL was set as the primary outcome and assessed at baseline and at the end of the investigation using the Short-Form 36 (SF-36) health survey. Body composition was analyzed using dual-energy X-ray absorptiometry (DXA). Physical activity was calculated using the International Physical Activity Questionnaire (IPAQ). After 16 weeks, despite there being no adherence to the Mediterranean Diet Serving Score (MDSS), supplemented individuals experienced significant HRQOL improvement $(+5.3 \% ; p=0.001)$, including enhanced perceived physical $(+11.2 \% ; p=0.002)$ and mental health $(+4.1 \% ; p=0.021)$ components, with bodily pain, vitality, and general health being the greatest contributors. Body fat mass significantly decreased $(-1.2 \mathrm{~kg} ; p=0.033)$, mainly within the trunk area $(-1.0 \mathrm{~kg} ; p=0.002)$. Engagement in physical activity significantly increased (+1308 Metmin (Metabolic Equivalent Task minutes)/week; $p=0.050$ ). Hence, chronic supplementation with nutritional diversity and dosing of a Mediterranean diet-inspired, polyphenol-rich ingredient resulted in significant amelioration in both perceived physical and mental health, concomitant with the improvement of body composition, in healthy subjects with excessive adiposity.
\end{abstract}

Keywords: health-related quality of life; vitality; body composition; phenolic compounds; Mediterranean diet

\section{Introduction}

The World Health Organization (WHO) defines quality of life (QOL) as "an individual's perception of their position in life in the context of culture and value systems in which 
they live, and in relation to their goals, expectations, standards, and concerns" [1]. Such conception of QOL is subjective, multidimensional, and encompasses a broad range of life domains, among which health is one of the most important determinants.

In addition to being an objective medical evaluation, the health-related quality of life (HRQOL), which typically combines physical, psychological, and social domains of health [2], is more recognized as a central outcome in healthcare strategies, highlighting the fact that health is deeply intertwined with a patient's perspective. Accordingly, the use of HRQOL assessment is particularly relevant and is increasingly widespread in clinical practices [3], predominantly for ageing populations and for the inherent expansion in the prevalence of non-communicable diseases (NCDs), which include cardiovascular diseases, diabetes mellitus, and hypertension. NCDs are currently the leading cause of mortality in the modern world, contributing to 38 million deaths each year [4]. According to WHO, the global burden of NCDs is imputable to ageing, rapid urbanization, and to globalization of unhealthy lifestyles.

Among modifiable risk factors, overweight and obesity are significant contributors to the high prevalence rate of $\mathrm{NCDs}$, making them the priority target in various public health programs [5]. A major cause of overweight and obesity is the excessive accumulation of body fat due to an imbalance between energy consumption and expenditure, particularly in populations with sedentary behaviors. The accumulation of body fat, predominantly within the abdominal region, is clearly associated with a chronic low-grade inflammatory state and an impaired redox status [6], both being principal pathological pathways involved in the development of NCDs. It is noteworthy that such disorders are also identified as validated metabolic indicators of ageing [7], suggesting that overweight and obesity are conditions that could potentially accelerate ageing and exacerbate the risk of ageing-linked NCDs [8].

In addition to their role in the etiology of these common medical conditions, overweight and obesity have profound adverse physical, social, and psychological consequences that can negatively affect HRQOL and impair everyday life [9,10], which appears to be an increasingly important outcome for patients and clinicians, as well as for policymakers. As a result, QOL has become a valuable endpoint assessed in both epidemiological and interventional weight management studies in overweight and obese volunteers [11-13]. Measuring HRQOL is the subjective perception of one's health, where patients are asked to rate several aspects of their life. Numerous studies have demonstrated that self-rated health measures are important predictors of mortality in various populations [14].

The Short-Form 36 Health survey (SF-36), a commonly used measure in HRQOL research, is a generic methodology developed and validated in the Medical Outcomes Study [15] that assesses eight important HRQOL domains that encompass health-related social, physical, and mental dimensions. The reliability of this questionnaire has been validated both in a healthy population [16] and among people with chronic and acute health conditions, but also when comparing between different groups of patients [10]. Furthermore, several authors have demonstrated a negative correlation between BMI and SF-36 scores $[17,18]$, and also an improvement of HRQOL correlated with weight loss in overweight people [13].

Among the dietary patterns, which are mostly studied for their health effects, it appears that adherence to the Mediterranean diet has been correlated to a lower risk for NCDs [19]; it is assumed that particular bioactive constituents of the Mediterranean diet, namely polyphenols, significantly contribute to the reported health-promoted effects [20]. Moreover, along with their widely studied antioxidant properties, recent studies demonstrate the modulatory effects of phenolic compounds on various cellular signaling pathways and responses, such as inflammation and energy metabolism [21,22], highlighting the complex mode of their individual mechanism of action in preventing NCDs [23]. Emerging large cohort studies that investigated the Mediterranean diet, specifically the regular consumption of a diversity of its main polyphenol content, have shown a posi- 
tive correlation to HRQOL [24,25], suggesting that such bioactive constituents might be beneficial in improving overweight- and obesity-linked impaired HRQOL.

The aim of this clinical study was to investigate whether 16 weeks of supplementation with an accurately characterized ingredient formulated from extracts of certain fruits and vegetables commonly consumed within the Mediterranean diet could improve HRQOL in overweight and obese, but otherwise healthy, subjects.

\section{Materials and Methods}

\subsection{Subjects}

Ninety-two healthy overweight and obese subjects were recruited through advertisements in the region of Murcia in southern Spain. Both men and women between the ages of 25-55 years, being overweight to obese (BMI: $25-40 \mathrm{~kg} / \mathrm{m}^{2}$ ) but otherwise healthy, were included in the study. Subjects were excluded if they: had a metabolic or chronic disease; had an allergy to carrot, grape, grapefruit, green tea, caffeine, or to guarana; were involved at the time of recruitment or within the previous 6 months in a chronic supplementation program, engaged in smoking cessation, or had high alcohol consumption; were pregnant or were breastfeeding; were in menopause; were suffering depression; or were involved in physical activity more than twice a week.

The study was approved by the Universidad Católica San Antonio de Murcia (UCAM), Spain) Ethics Committee (approval $\mathrm{N}^{\circ}$ 5551) and conducted per the guidelines laid out in the Declaration of Helsinki [26] and in compliance with Good Clinical Practices defined in the ICH Harmonized Tripartite Guideline [27]. All participants were informed about the study procedures and signed written informed consent before entering the study. This trial was registered at clinicaltrials.gov as NCT03423719.

\subsection{Test Supplement}

Fiit-ns ${ }^{\circledR}$, developed by FYTEXIA (France), is principally obtained by alcohol and water extraction of grapefruit (Citrus paradisi Macfad), grape (Vitis vinifera L.), and guarana seed (Paullinia cupana Kunth); by water extraction of green tea (Camellia sinensis L. Kuntze) and black carrot (Daucus carota L.). Fiit-ns ${ }^{\circledR}$ provides bioactive compounds, specifically polyphenols from the flavonoid family, and natural components of the methylxanthine family to from an extract of guarana seeds, as well as vitamin B3. The placebo product was $100 \%$ maltodextrin, which is polyphenol-, methylxanthine- and vitamin B3-free. Both Fiit-ns ${ }^{\circledR}$ and placebo were supplied in $450 \mathrm{mg}$ capsules of identical appearance and flavor.

The supplement was analyzed by means of high-performance liquid chromatography (HPLC). An Agilent HPLC 1260 apparatus (Agilent Technologies, Les Ulis, France) using software Openlab CDS Chemstation Edition (version 1.3.1) coupled with a diode array detector was used. Separations were carried out by means of a Zorbax Stablebond SBC18 column $(4.6 \times 150 \mathrm{~mm} ; 5 \mu \mathrm{m}$ particle size). To detect different phenolic classes, two different analytical methods were adopted: one for bioflavonoids and caffeine and one for anthocyanins.

For flavonoids and caffeine, mobile phase A consisted of water, mobile phase B was acetic acid, and mobile phase $C$ was 100\% acetonitrile. The linear gradient program was used as follows: (a) 0 to $5 \mathrm{~min} 94 \% \mathrm{~A}$ and $6 \% \mathrm{~B}$; (b) 5 to $10 \mathrm{~min} 82.4 \% \mathrm{~A}, 5.6 \% \mathrm{~B}$, and $12 \%$ C; (c) 10 to $15 \mathrm{~min} 76.6 \% \mathrm{~A}, 5.4 \% \mathrm{~B}$, and $18 \%$ C; (d) 15 to $25 \min 67.9 \% \mathrm{~A}, 5.1 \% \mathrm{~B}$, and $27 \%$ C; (e) 25 to $30 \mathrm{~min} 65 \% \mathrm{~A}, 5 \% \mathrm{~B}$, and 30\% C; (f) 30 to $35100 \%$ C; (g) 35 to $40 \mathrm{~min}$ $100 \%$ C; (h) 40 to $45 \mathrm{~min} 64 \% \mathrm{~A}$ and 6\% B. Monitoring was performed at $280 \mathrm{~nm}$ at a flow rate of $1 \mathrm{~mL} / \mathrm{min}$ and injection volume of $25 \mu \mathrm{L}$. Flavanones, flavanols, and caffeine were respectively expressed as naringin, catechin, and caffeine.

Regarding anthocyanins, mobile phase A was water, mobile phase B consisted of formic acid, and mobile phase $C$ was acetonitrile. The gradient program used is described as follows: (a) 0 to $5 \mathrm{~min} 84.18 \% \mathrm{~A}, 10 \% \mathrm{~B}$, and $5.82 \% \mathrm{C}$; (b) 5 to $20 \mathrm{~min} 77.6 \% \mathrm{~A}, 10 \% \mathrm{~B}$, and $12.4 \% \mathrm{C}$; (c) 20 to $35 \mathrm{~min} 68.2 \% \mathrm{~A}, 10 \% \mathrm{~B}$, and $21.8 \% \mathrm{C}$; (d) 35 to $40 \mathrm{~min} 58.8 \% \mathrm{~A}, 10 \% \mathrm{~B}$, and $31.2 \%$ C; (e) 40 to $45 \min 44.7 \% \mathrm{~A}, 10 \% \mathrm{~B}$, and $45.3 \% \mathrm{C}$; (f) 45 to $50 \mathrm{~min} 44.7 \% \mathrm{~A}, 10 \%$ B, and 
$45.3 \% \mathrm{C}$; (g) 50 to $60 \mathrm{~min} 40 \% \mathrm{~A}, 10 \% \mathrm{~B}$, and 50\% C; (h) 60 to $65 \mathrm{~min} 84.18 \% \mathrm{~A}, 10 \% \mathrm{~B}$, and $5.82 \% \mathrm{C}$. Monitoring was performed at $520 \mathrm{~nm}$ at a flow rate of $0.8 \mathrm{~mL} / \mathrm{min}$ and injection volume of $10 \mu \mathrm{L}$. Anthocyanins were expressed as cyanidin 3-O-glucoside equivalents.

Naringin, catechin, and caffeine standards were purchased from Sigma-Aldrich Co. (St. Louis, MO, USA) and cyanidin 3-O-glucoside standard was purchased from Extrasynthese (Genay, France).

\subsection{Study Design and Interventions}

The study was designed as a 16 week, randomized, double-blinded, placebo-controlled clinical trial. Eligible participants were randomized using a simple block randomization of 1:1 with an additional stratification for sex (40\% minimum and 60\% maximum each sex), with a separated randomization list using computer-generated random numbers. Allocation concealment was achieved with sealed opaque envelops. Once enrolled, subjects received either the supplement $(n=43)$ or a visually identical placebo $(n=49)$. They were instructed to take two capsules daily for 16 weeks, one in the morning at breakfast and one at lunchtime.

Throughout the course of the study, volunteers were instructed by a dietitian to consume a normal caloric and balanced diet corresponding to their individual needs by determining their specific resting energy expenditure (REE), calculated from the revised Harris-Benedict equation and adjusted per individual level of physical activity [28]. At baseline $\left(W_{1}\right)$, volunteers performed a $24 \mathrm{~h}$ diet recall interview corresponding to the consumption of two days during the previous week and one day during the previous weekend, in order to evaluate their usual dietary habits. At the end of the studied period, the same interview was performed to check compliance with dietary instructions. A difference of $\pm 10 \%$ between the reported and recommended intakes at the end of the study was considered as satisfactory. Moreover, general adherence to the Mediterranean dietary pattern was assessed using the Mediterranean Diet Serving Score (MDSS) [29]. This score ranges from 0 to 24, with an optimal cut-off point of 13.5, which discriminates adherent and non-adherent individuals.

Subjects were also encouraged to maintain their usual level of physical activity throughout the 16-week-long intervention period. The subjects were provided with a pedometer (HJ-321, Omron Healthcare), which was worn at the hip, to record the physical mobility as the number of daily steps. Subjects reported their daily level of activity in a diary.

Subjects reported to the UCAM Research Center for 5 visits: (i) pre-inclusion visit at week $0\left(\mathrm{~W}_{0}\right)$ to verify the subject's eligibility, to assess anthropometrics, and to collect blood samples for the evaluation of safety parameters; (ii) baseline visit $\left(\mathrm{W}_{1}\right)$; (iii) follow-up visits $\left(\mathrm{W}_{4}, \mathrm{~W}_{8}\right.$, and $\left.\mathrm{W}_{12}\right)$; and final visit $\left(\mathrm{W}_{16}\right)$. During each visit, subjects returned their physical activity diary and the unused investigational supplements and were questioned about possible occurrence of adverse events before they were provided with a new pill dispenser for the 4 following weeks.

\subsection{Measurements}

\subsubsection{Health-Related Quality of Life}

HRQOL was measured at baseline $\left(\mathrm{W}_{1}\right)$ and at the end of the intervention period $\left(\mathrm{W}_{16}\right)$ using the Spanish version of the 36-item Short Form (SF-36) health survey [30]. This generic instrument assesses participants' self-reported HRQOL across physical and mental components. Questions pertained to the individuals' typical day during the past four weeks and usual experiences. The 36 questions were distributed across eight subscales: physical function (PF), role-physical (RP) limitations caused by physical problems, bodily pain (BP), general health $(\mathrm{GH})$ perception, vitality $(\mathrm{VT})$, social functioning $(\mathrm{SF})$, role-emotional (RE) limitations caused by emotional problems, and emotional well-being (EWB). The eight dimensions ranged in score from 0 to 100, with higher scores indicating better HRQOL. 
The SF-36 also included one Physical Component Summary (PCS) score and one Mental Component Summary (MCS) score, as well as an overall score of quality of life.

\subsubsection{Body Composition}

At baseline $\left(\mathrm{W}_{1}\right)$ and at the end of the study period $\left(\mathrm{W}_{16}\right)$, body composition was assessed in the morning, with volunteers in a fasted state and wearing light clothing and no shoes.

Body weight $(\mathrm{kg})$ was measured with calibrated weighing scales (TBF-300MA, Tanita Corporation, IL, USA). Waist circumference $(\mathrm{cm})$ was measured at the narrowest point between the lowest rib and the iliac crest using a non-stretchable tape. The Index of Central Obesity (ICO) scores were calculated as the waist-to-height ratio.

Body fat mass was determined using a dual-energy X-ray absorptiometry (DXA) scan of the whole body (XR-46; Norland Corp., Fort Atkinson, WI, USA). Discrimination of whole-body fat mass (FM) and body trunk fat mass (TFM) was performed with a computerized software (Software Illuminatus DXA v.4.4.0, Visual MED, Inc., Charlotte, NC, USA and Norland CooperSurgical Company, Minneapolis, MN, USA) using standardized procedures.

\subsubsection{Self-Reported Physical Activity}

The self-reported International Physical Activity Questionnaire (IPAQ) instrument was used to determine global physical activity levels [31]. This self-administered, longform questionnaire consisted of 27 items that covered four different domains of physical activity (working, transportation, housework, and gardening and leisure-time) that occurred during the previous seven days. The results are presented as an estimation of energy expenditure in metabolic equivalent minutes per week (Met-min/week), and a categorical score was calculated to classify volunteers as inactive, moderately, or highly active. Volunteers completed the IPAQ questionnaire in the presence of an investigator at $\mathrm{W}_{1}$ and $\mathrm{W}_{16}$.

\subsubsection{Safety Parameters}

Safety parameters were assessed before inclusion into the study $\left(\mathrm{W}_{0}\right)$ and at the end of the intervention period $\left(\mathrm{W}_{16}\right)$ in order to verify and confirm the healthiness of the volunteers. Safety parameters included liver function parameters (alanine transaminase (ALT), aspartate aminotransferase (AST), gamma-glutamyltransferase (GGT)), renal function parameters (urea, creatinine, sodium $(\mathrm{Na})$, potassium $(\mathrm{K})$ ), and heart rate.

\subsection{Statistical Analysis}

Data sets were analyzed using XLSTAT-Biomed software (v. 2017.6 for Mac, Addinsoft, Paris, France). The data are expressed as the mean \pm standard deviation (SD). At baseline, the distribution was considered normal. Changes within and between groups at $W_{1}$ and $\mathrm{W}_{16}$ were analyzed using paired and unpaired Student's $t$-test, respectively. To compare baseline differences between the SF-36 scales and population norms, one sample $t$-test was used. A minimum value of $p \leq 0.05$ was selected as the threshold for statistical significance.

The primary outcome addressed in this study was the difference in SF-36 total scores after the 16 week intervention period. The power calculation was based on the previous results of a pilot study conducted with Fiit-ns ${ }^{\circledR}[32](\alpha=0.05$, power $(1-\beta)=0.8)$ and was performed based on an expected clinical difference in SF-36 total scores between $\mathrm{W}_{1}$ and $\mathrm{W}_{16}$ within the supplemented group of a $+5 \%$ benefit minimum to determine the targeted final sample size ( $n=28$ per group). Considering a drop-out rate of $20 \%$ and failure rate risk of $20 \%$, inclusion of 92 subjects was recommended. 


\section{Results}

\subsection{Characterization of the Supplement}

The total bioactive content corresponds to $29.27 \mathrm{~g} / 100 \mathrm{~g}$ dry matter, with a total flavonoid content measured at $24.75 \mathrm{~g} / 100 \mathrm{~g}$. The flavanol content corresponded to $15.67 \mathrm{~g} / 100 \mathrm{~g}$ and included catechin, epigallocatechin gallate, epicatechin, and epicatechin gallate, respectively, measured at $1.47,9.55,2.37$, and $2.28 \mathrm{~g} / 100 \mathrm{~g}$. The flavanone content corresponded to $8.91 \mathrm{~g} / 100 \mathrm{~g}$, among which isonaringin, naringin, hesperidin, and neohesperidin contents were $0.54,7.65,0.03$, and $0.13 \mathrm{~g} / 100 \mathrm{~g}$, respectively, whereas total unidentified flavanone was evaluated as the naringin equivalent at $0.56 \mathrm{~g} / 100 \mathrm{~g}$. The total anthocyanin content corresponded to $0.17 \mathrm{~g} / 100 \mathrm{~g}$ as the kuromanin equivalent. The caffeine content was measured at $4.52 \mathrm{~g} / 100 \mathrm{~g}$ and a third-party laboratory measured the vitamin B3 content at $2.02 \mathrm{~g} / 100 \mathrm{~g}$ (Table 1).

Table 1. Characterization of phenolic compounds and caffeine present in the supplement.

\begin{tabular}{|c|c|c|c|c|}
\hline \multirow{2}{*}{ Compound } & \multirow{2}{*}{ Rt (min) } & \multirow{2}{*}{$\Lambda \operatorname{Max}(\mathrm{nm})$} & \multicolumn{2}{|c|}{ Content (mg/100 g) } \\
\hline & & & Mean & SD \\
\hline Caffeine & 13.5 & 273 & 4523.2 & $(450.4)$ \\
\hline Catechin & 9.0 & 278 & 1472.9 & $(85.1)$ \\
\hline Epigallocatechin Gallate & 11.9 & 274 & 9549.9 & (282.9) \\
\hline Epicatechin & 12.8 & 280 & 2373.0 & $(416.6)$ \\
\hline Epicatechin Gallate & 15.8 & 278 & 2279.3 & (372.9) \\
\hline Flavanone-like 1 & 16.1 & $284 / 323$ & 97.6 & $(27.7)$ \\
\hline Isonaringin & 18.6 & $284 / 330$ & 540.8 & (156.1) \\
\hline Naringin & 19.5 & $284 / 330$ & 7646.9 & $(66.3)$ \\
\hline Hesperidin & 20.3 & $284 / 328$ & 25.4 & $(24.3)$ \\
\hline Neohesperidin & 21.2 & $284 / 328$ & 134.2 & $(86.8)$ \\
\hline Flavanone-like 2 & 27.6 & $284 / 329$ & 263.5 & $(4.0)$ \\
\hline Flavanone-like 3 & 30.4 & $289 / 328$ & 196.4 & $(15.3)$ \\
\hline Cyanidin-3-xylosylglucosylgalactoside & 6.2 & 516 & 9.5 & $(2.0)$ \\
\hline Cyanidin-3-xylosylgalactoside & 7.9 & 518 & 39.3 & $(7.4)$ \\
\hline Cyanidin-3-sinapoylxylosylglucosylgalactoside & 11.2 & 531 & 13.8 & $(1.5)$ \\
\hline Cyanidin-3-feruloylxylosylglucosylgalactoside & 12.4 & 528 & 106.1 & $(13.1)$ \\
\hline Cyanidin-3-pcoumarylxylosylglucosylgalactoside & 14.3 & 528 & 3.0 & $(1.6)$ \\
\hline
\end{tabular}

\subsection{Baseline Characteristics}

From the 92 individuals who were randomly allocated to either the supplement $(n=43)$ or the placebo $(n=49), 78$ subjects completed the 16 week intervention $(85 \%$ of the randomly assigned subjects); after having started the intervention, a total of 14 volunteers dropped out for personal reasons, including 6 within the supplemented group and 8 within the placebo group. Moreover, at the end of the study period, 6 subjects were excluded from final analysis because of protocol deviation, including 2 subjects within the supplemented group and 4 within the placebo group who either did not complete the SF-36 questionnaire or who were non-compliant with the protocol. Finally, 72 volunteers were included in the analysis, with 35 individuals in the supplemented and37 individuals in the placebo group (Figure 1). Baseline data of the study population are presented in Table 2. The two groups were similar with respect to age, height, body weight, and SF-36 total scores. At baseline, the placebo group had a significantly higher average BMI compared with the supplemented group. 


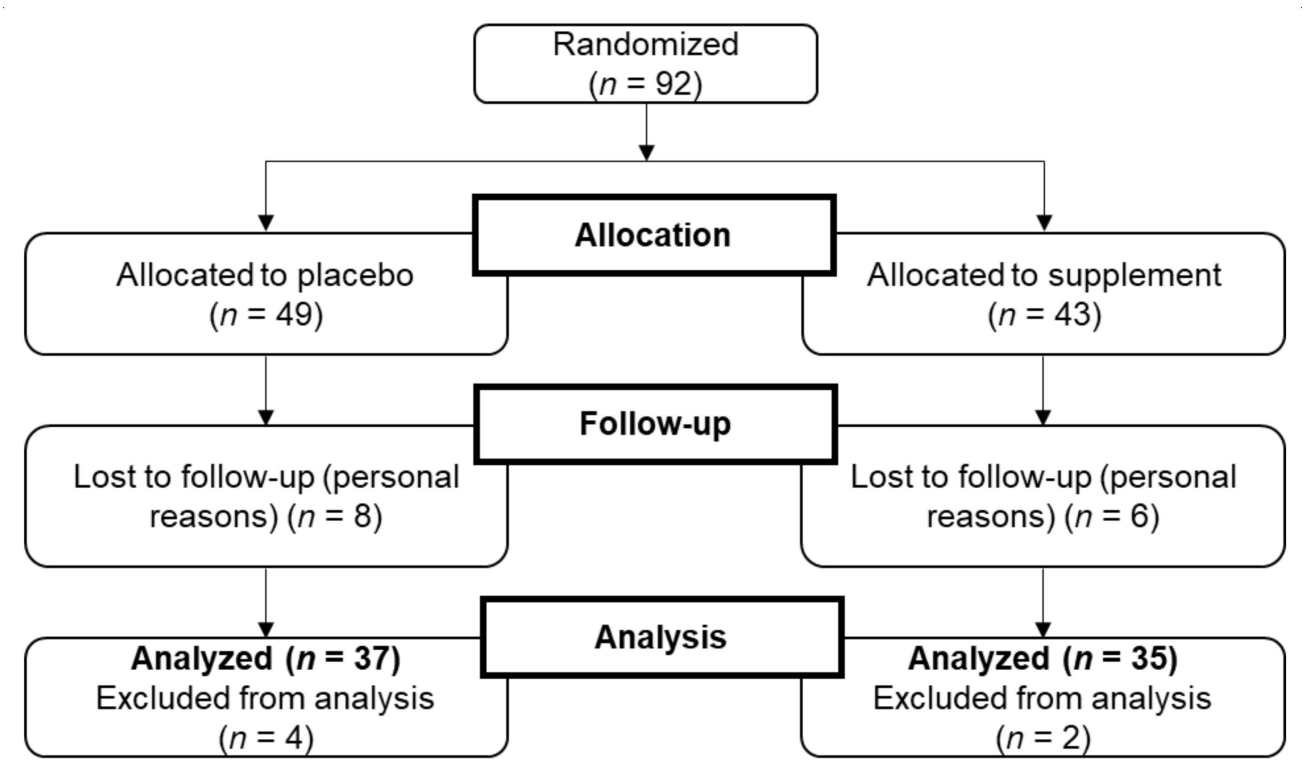

Figure 1. CONSORT (Consolidated Standards of Reporting Trials) flow diagram of study.

Table 2. Baseline characteristics of the study population.

\begin{tabular}{ccccccc}
\hline Variable & \multicolumn{3}{c}{ Whole Population } & \multicolumn{2}{c}{ Placebo Group } & \multicolumn{2}{c}{$\begin{array}{c}\text { Supplemented } \\
\text { Group }\end{array}$} \\
\hline Subjects, $n(\mathrm{M} / \mathrm{F})$ & \multicolumn{2}{c}{$72(34 / 38)$} & \multicolumn{2}{c}{$37(16 / 21)$} & \multicolumn{2}{c}{$35(18 / 17)$} \\
& Mean & SD & Mean & SD & Mean & SD \\
Age (years) & 40 & $(6)$ & 41 & $(6)$ & 39 & $(7)$ \\
Height (meters) & 1.69 & $(0.09)$ & 1.68 & $(0.08)$ & 1.70 & $(0.11)$ \\
Body weight (kg) & 87.0 & $(12.6)$ & 89.3 & $(12.2)$ & 84.5 & $(12.6)$ \\
BMI (kg/m $\left.{ }^{2}\right)$ & 30.5 & $(3.5)$ & 31.6 & $(4.0)$ & $29.3 *$ & $(2.5)$ \\
SF-36 score (points) & 81.6 & $(9.2)$ & 81.7 & $(8.2)$ & 81.5 & $(10.3)$ \\
*-Significant at $p \leq 0.05$ level; M-male; F-female; BMI-Body mass index; SF-36-Short form 36 Health survey.
\end{tabular}

\subsection{Health-Related Quality of Life}

Regarding the whole population at baseline (Table 3), SF-36 subscales regarding vitality, emotional well-being, and mental component scores were significantly lower than the age-specific populations norms taken from the Spanish population reference values [33]. At $\mathrm{W}_{1}$, placebo and supplemented groups exhibited similar SF-36 scores, including both individual domains and summary scores (Table 4$)$. After 16 weeks of supplementation, the supplemented group experienced a significant $+5.3 \%$ increase $(p=0.001)$ (Figure 2$)$ in total SF-36 score, while no change was observed in the total score of the placebo group. The supplemented group showed statistically significant improvements in five out of eight domains of the health-related quality of life. Respective improvements were observed for the physical component summary (PCS; $+11.2 \%, p=0.002$ ), including physical functioning $(\mathrm{PF} ;+5.5 \%, p=0.006)$, bodily pain $(\mathrm{BP} ;+11.2 \%, p=0.028)$, and general health $(\mathrm{GH}$; $+7.2 \%, p=0.010)$, as well as for the mental component summary (MCS; $+4.1 \%, p=0.021$ ), which included vitality $(\mathrm{VT} ;+7.8 \%, p=0.006)$ and emotional well-being $(\mathrm{EWB} ;+5.2 \%$, $p=0.021$ ). No statistically significant changes were shown within the placebo group after the 16 week intervention. 


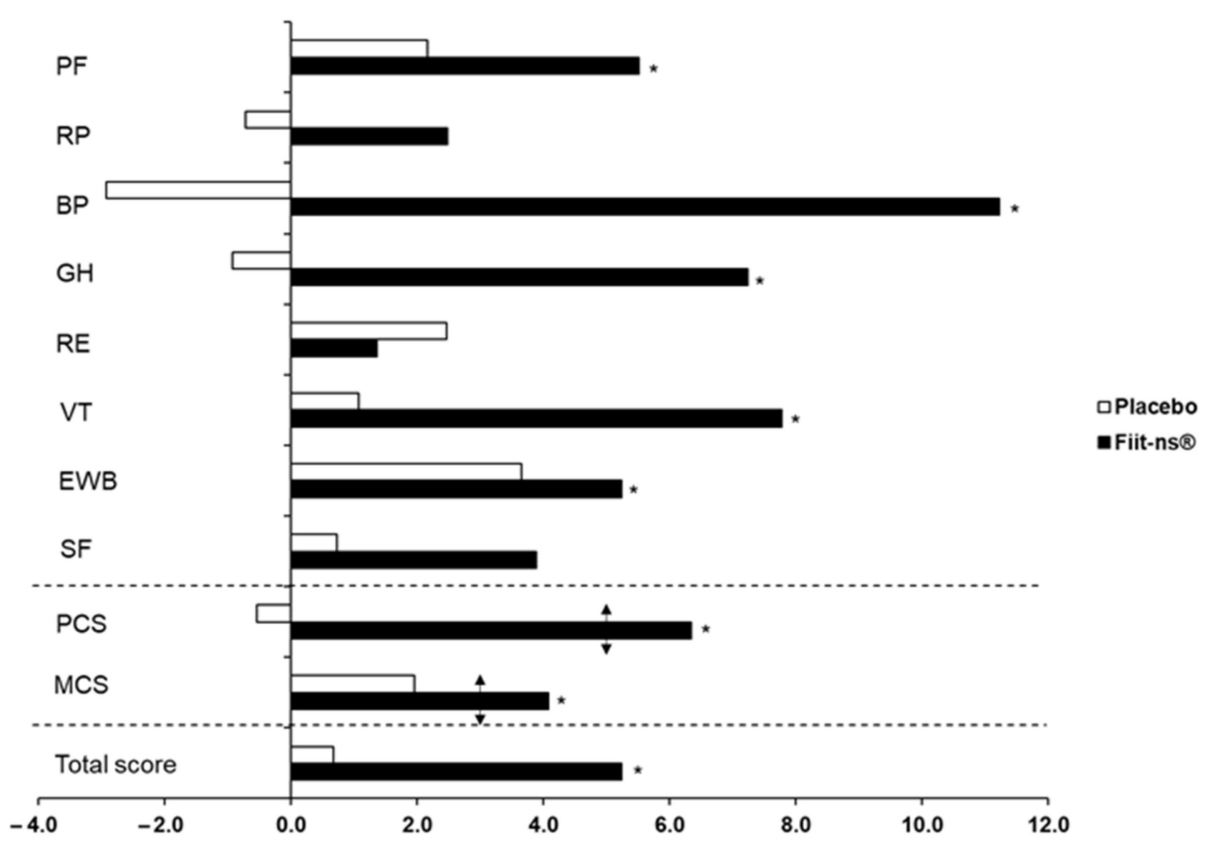

Figure 2. The percentage changes from baseline $\left(\mathrm{W}_{1}\right)$ to the end of the study $\left(\mathrm{W}_{16}\right)$ in individual SF-36 domains, as well as in the Physical Component Score (PCS), Mental Component Score (MCS), and total HRQOL score in placebo and in supplemented subjects. Arrows indicate clinically significant differences according to Samsa et al. [31]. Note: *-Indicates an intragroup difference between baseline $\left(\mathrm{W}_{1}\right)$ and end of the study $\left(\mathrm{W}_{16}\right)$ at $p \leq 0.05$ level. PF-physical functioning; $\mathrm{RP}$-role physical; BP—bodily pain; GH—general health; RE-role emotional; VT—vitality; EWB-emotional well-being; $\mathrm{SF}$ - social functioning.

Table 3. Mean scores for SF-36 eight subscales at baseline in the study and in the Spanish population aged $25-54$.

\begin{tabular}{ccc}
\hline Scale & Baseline & Age Specific Population Norm ${ }^{\S}$ \\
\hline Physical component score & 83.8 & 83.0 \\
Physical functioning & 89.5 & 91.9 \\
Role-physical & 93.8 & 87.5 \\
Bodily pain & 79.0 & 82.6 \\
General health & 73.0 & 72.7 \\
Mental component score & $79.4^{*}$ & 82.3 \\
Role-emotional & 92.4 & 91.3 \\
Vitality & $62.8^{*}$ & 70.2 \\
Emotional well-being & $70.6^{*}$ & 74.9 \\
Social functioning & 91.8 & 92.9 \\
\hline
\end{tabular}

§-Combined score for men and women ages $25-54$ as the age-specific population norm; ${ }^{*}$-a significant difference at baseline from the age-specific population norm for the scale at $p \leq 0.05$ level.

\subsection{Body Composition}

At baseline, all fat-mass-related variables (FM, TFM, Index of Central Obesity (ICO), and BMI) were significantly higher in the placebo group (Table 5). Such a discrepancy is explained by the higher number of obese individuals that completed the clinical investigation in the placebo group. After 16 weeks of supplementation, volunteers from the placebo group did not experience any significant changes in body composition. The supplemented group showed an improvement in anthropometrics after 16 weeks, with a statistically significant decrease in body weight by $-1.3 \mathrm{~kg}(p=0.013)$ and in BMI by -0.4 points $(p=0.012)$. Waist size significantly decreased by $-1.1 \mathrm{~cm}(p=0.017)$, consequently lowering the ICO by $-1.3 \%(p=0.018)$. Supplemented volunteers significantly lost $-1.2 \mathrm{~kg}$ of FM $(p=0.033)$, of which $-1.0 \mathrm{~kg}$ was fat lost only from the TFM $(p=0.002)$. 
Table 4. Mean scores for SF-36 eight subscales, including both physical and mental components, and total health-related quality of life scores at baseline $\left(\mathrm{W}_{1}\right)$ and at the end of the study $\left(\mathrm{W}_{16}\right)$.

\begin{tabular}{|c|c|c|c|c|c|c|c|c|}
\hline \multirow{3}{*}{ Scale } & \multicolumn{4}{|c|}{ Placebo Group } & \multicolumn{4}{|c|}{ Supplemented Group } \\
\hline & \multicolumn{2}{|c|}{ W1 } & \multicolumn{2}{|c|}{ W16 } & \multicolumn{2}{|c|}{ W1 } & \multicolumn{2}{|c|}{ W16 } \\
\hline & Mean & SD & Mean & SD & Mean & SD & Mean & SD \\
\hline SF-36 Total score & 81.7 & $(8.2)$ & 82.2 & $(8.2)$ & 81.5 & $(10.3)$ & $85.8^{\mathrm{a} *}$ & $(6.4)$ \\
\hline Physical component score & 84.3 & $(7.6)$ & 83.8 & $(8.9)$ & 83.4 & $(12.6)$ & $88.7^{\mathrm{a} *}$ & $(7.6)$ \\
\hline Physical functioning & 88.6 & (9.4) & 90.6 & $(8.4)$ & 90.4 & $(12.7)$ & $95.4^{a *}$ & $(7.0)$ \\
\hline Role-physical & 94.3 & $(7.3)$ & 93.6 & $(8.1)$ & 93.4 & $(11.6)$ & 95.7 & $(6.6)$ \\
\hline Bodily pain & 80.7 & $(18.0)$ & 78.3 & $(23.3)$ & 77.1 & $(22.9)$ & $85.8 *$ & (14.5) \\
\hline General health & 73.5 & (13.3) & 72.8 & (11.7) & 72.5 & $(16.0)$ & $77.8^{*}$ & $(13.7)$ \\
\hline Mental component score & 79.1 & $(10.8)$ & 80.7 & (10.5) & 79.7 & $(10.7)$ & $82.9 *$ & $(8.0)$ \\
\hline Role-emotional & 91.2 & $(14.8)$ & 93.5 & $(12.6)$ & 93.6 & $(12.0)$ & 94.9 & $(9.2)$ \\
\hline Vitality & 62.4 & $(11.1)$ & 63.1 & $(12.2)$ & 63.1 & $(13.4)$ & $68.0^{\mathrm{a} *}$ & $(11.1)$ \\
\hline Emotional well-being & 70.9 & $(11.1)$ & 73.5 & $(10.9)$ & 70.3 & $(12.9)$ & $73.9 *$ & $(10.0)$ \\
\hline Social functioning & 91.9 & $(15.9)$ & 92.6 & (14.9) & 91.8 & $(12.1)$ & 95.4 & $(9.1)$ \\
\hline
\end{tabular}

*-An intragroup difference between baseline $\left(\mathrm{W}_{1}\right)$ and end of the study $\left(\mathrm{W}_{16}\right)$ at $p \leq 0.05$; - an intergroup difference at the end of the study $\left(\mathrm{W}_{16}\right)$ at $p \leq 0.05$.

Table 5. Body weight, BMI, waist circumference, ICO, total body fat mass, and total trunk fat mass scores at baseline $\left(\mathrm{W}_{1}\right)$ and at the end of the study $\left(\mathrm{W}_{16}\right)$.

\begin{tabular}{|c|c|c|c|c|c|c|c|c|}
\hline & \multicolumn{4}{|c|}{ Placebo Group } & \multicolumn{4}{|c|}{ Supplemented Group } \\
\hline & \multicolumn{2}{|c|}{ W1 } & \multicolumn{2}{|c|}{ W16 } & \multicolumn{2}{|c|}{ W1 } & \multicolumn{2}{|c|}{ W16 } \\
\hline & Mean & SD & Mean & SD & Mean & SD & Mean & SD \\
\hline Body weight, kg & 89.3 & $(12.2)$ & 89.1 & $(12.5)$ & 84.5 & $(12.6)$ & $83.2^{b *}$ & $(12.6)$ \\
\hline BMI, $\mathrm{kg} / \mathrm{m}^{2}$ & 31.6 & $(4.0)$ & 31.5 & $(3.9)$ & $29.3^{a}$ & $(2.5)$ & $28.9^{b *}$ & $(2.8)$ \\
\hline Waist circumference, $\mathrm{cm}$ & 94.2 & $(9.7)$ & 94.6 & $(9.3)$ & 90.7 & $(8.8)$ & $89.6^{\mathrm{b} *}$ & (9.3) \\
\hline ICO & 0.560 & $(0.05)$ & 0.563 & $(0.05)$ & $0.533^{a}$ & $(0.04)$ & $0.526^{b *}$ & $(0.04)$ \\
\hline Total body fat mass, $\mathrm{kg}$ & 35.2 & (10.4) & 35.2 & (10.8) & $30.5^{a}$ & $(7.4)$ & $29.3^{b *}$ & $(7.9)$ \\
\hline Total trunk fat mass, $\mathrm{kg}$ & 18.1 & $(5.4)$ & 18.1 & $(5.9)$ & $15.7^{\mathrm{a}}$ & (4.1) & $14.7^{b *}$ & (4.2) \\
\hline
\end{tabular}

*-An intragroup difference between baseline $\left(\mathrm{W}_{1}\right)$ and end of the study $\left(\mathrm{W}_{16}\right)$ at $p \leq 0.05$; ${ }^{\mathrm{a}, \mathrm{b}}$-intergroup differences at baseline $\left(\mathrm{W}_{1}\right)$ and at the end of the study $\left(\mathrm{W}_{16}\right)$ at $p \leq 0.05$.

\subsection{Self-Reported Physical Activity and Average Daily Steps Recording}

At baseline, both groups showed similar self-reported levels of physical activity. While it did not significantly change within the placebo population $(p=0.280)$, the supplemented subjects showed an increase of +1308 Met-min/week $(p=0.05)$ after 16 weeks of supplementation (Table 6). Regarding categorical scores at baseline, the rates of volunteers within each category (i.e., inactive, moderately active, and highly active) were similar between groups. After 16 weeks, the rates of inactive people remained the same in both groups; within the placebo group, the rate of highly active subjects decreased by $-43 \%$, while the rate of moderately active individuals increased by $+14 \%$. In contrast, within the supplemented population, the rate of moderately active subjects decreased by $-14 \%$ but the number of highly active individuals increased by $+43 \%$. The number of average daily steps was significantly different at baseline between placebo and supplemented subjects $(p=0.028)$. The placebo group did not experience any significant change in average daily steps monitored after 16 weeks, while the supplemented subjects significantly decreased their average rate by -678 steps $(p=0.019)$ to reach a similar level to the placebo population. 
Table 6. Mean total score for self-reported physical activity (IPAQ, International Physical Activity Questionnaire) and daily number of steps (pedometer) at baseline $\left(\mathrm{W}_{1}\right)$ and at the end of the study $\left(\mathrm{W}_{16}\right)$.

\begin{tabular}{|c|c|c|c|c|c|c|c|c|}
\hline & \multicolumn{4}{|c|}{ Placebo Group } & \multicolumn{4}{|c|}{ Supplemented Group } \\
\hline & \multicolumn{2}{|c|}{ W1 } & \multicolumn{2}{|c|}{ W16 } & \multicolumn{2}{|c|}{ W1 } & \multicolumn{2}{|c|}{ W16 } \\
\hline & Mean & SD & Mean & SD & Mean & SD & Mean & SD \\
\hline $\begin{array}{c}\text { IPAQ score } \\
\text { (Met-min/week) }\end{array}$ & 4798 & $(4740)$ & 4231 & $(4190)$ & 4766 & $(4721)$ & $6074 *$ & $(6631)$ \\
\hline Inactive $(\%)$ & \multicolumn{2}{|c|}{15.2} & \multicolumn{2}{|c|}{15.2} & \multicolumn{2}{|c|}{12.5} & \multicolumn{2}{|c|}{12.5} \\
\hline Moderately active (\%) & \multicolumn{2}{|c|}{63.6} & \multicolumn{2}{|c|}{72.7} & \multicolumn{2}{|c|}{65.6} & \multicolumn{2}{|c|}{56.3} \\
\hline Highly active (\%) & \multicolumn{2}{|c|}{21.2} & \multicolumn{2}{|c|}{12.1} & \multicolumn{2}{|c|}{21.8} & \multicolumn{2}{|c|}{31.2} \\
\hline Daily steps & $\begin{array}{c}\text { Mean } \\
6770\end{array}$ & $\begin{array}{c}\mathrm{SD} \\
(2239)\end{array}$ & $\begin{array}{l}\text { Mean } \\
7186\end{array}$ & $\begin{array}{l}\text { SD } \\
(2679)\end{array}$ & $\begin{array}{l}\text { Mean } \\
8169^{a}\end{array}$ & $\begin{array}{c}\text { SD } \\
(2797)\end{array}$ & $\begin{array}{l}\text { Mean } \\
7491 *\end{array}$ & $\begin{array}{c}\text { SD } \\
(2964)\end{array}$ \\
\hline
\end{tabular}

*-An intragroup difference between baseline $\left(\mathrm{W}_{1}\right)$ and end of the study $\left(\mathrm{W}_{16}\right)$ at $p \leq 0.05$; ${ }^{\mathrm{a}}$-an intergroup difference at baseline $\left(\mathrm{W}_{1}\right)$ at $p \leq 0.05$. MET-min/week-Metabolic Equivalent Task minutes per week.

\subsection{Recommended and Reported Dietary Intake}

Recommended intake at baseline did not differ between the two groups $(p=0.770)$ (Table 7). When recommended intake was compared with reported intake at baseline, the differences were $-13.7 \%$ and $-7.8 \%$ for the placebo and supplemented groups, respectively. After 16 weeks, the differences between recommended and reported intake in both groups were lower than $10 \%(-8.8 \%$ and $-9.0 \%$ for the placebo and for the supplemented groups, respectively). Mediterranean Diet Serving Scores (MDSS) were similar between both groups at 8.4 and 8.6 for placebo and supplemented populations, respectively, indicating a non-adherence to the Mediterranean diet pattern during the intervention period.

Table 7. Recommended and reported dietary intake at baseline $\left(\mathrm{W}_{1}\right)$ and at the end of the study $\left(\mathrm{W}_{16}\right)$.

\begin{tabular}{|c|c|c|c|c|c|c|c|c|}
\hline & \multicolumn{4}{|c|}{ Placebo Group } & \multicolumn{4}{|c|}{ Supplemented Group } \\
\hline & \multicolumn{2}{|c|}{ W1 } & \multicolumn{2}{|c|}{ W16 } & \multicolumn{2}{|c|}{ W1 } & \multicolumn{2}{|c|}{ W16 } \\
\hline & Mean & SD & Mean & SD & Mean & SD & Mean & SD \\
\hline Recommended intake (Kcal) & 2074 & $(273)$ & 2084 & $(281)$ & 2096 & $(360)$ & 2039 & $(342)$ \\
\hline Reported intake (Kcal) & 1789 & $(471)$ & $1899 *$ & $(502)$ & 1933 & $(463)$ & 1855 & (392) \\
\hline & \multicolumn{2}{|c|}{ Mean } & \multicolumn{2}{|c|}{ SD } & \multicolumn{2}{|c|}{ Mean } & \multicolumn{2}{|c|}{ SD } \\
\hline MDSS score & \multicolumn{2}{|c|}{8.4} & \multicolumn{2}{|c|}{ (3.7) } & \multicolumn{2}{|c|}{8.6} & \multicolumn{2}{|c|}{$(4.2)$} \\
\hline
\end{tabular}

*-An intragroup difference between baseline $\left(\mathrm{W}_{1}\right)$ and end of the study $\left(\mathrm{W}_{16}\right)$ at $p \leq 0.05$.

\subsection{Safety}

After 16 weeks, both liver and renal function parameters were within the healthy range in both groups, suggesting that no health impairment occurred throughout the course of the study. Moreover, heart rates stayed stable throughout the course of the study (Table 8). No adverse events or side effects linked to the supplement were reported during the course of the study. 
Table 8. Clinical safety values at baseline $\left(\mathrm{W}_{1}\right)$ and at the end of the study $\left(\mathrm{W}_{16}\right)$.

\begin{tabular}{|c|c|c|c|c|c|c|c|c|}
\hline \multirow{3}{*}{ Parameters (Normal Range) } & \multicolumn{4}{|c|}{ Placebo Group } & \multicolumn{4}{|c|}{ Supplemented Group } \\
\hline & \multicolumn{2}{|c|}{ W1 } & \multicolumn{2}{|c|}{ W16 } & \multicolumn{2}{|c|}{ W1 } & \multicolumn{2}{|c|}{ W16 } \\
\hline & Mean & SD & Mean & SD & Mean & SD & Mean & SD \\
\hline \multicolumn{9}{|l|}{ Liver function } \\
\hline ALT (7-55 U/L) & 21.4 & (9.1) & 21.0 & $(8.5)$ & 25.0 & $(15.9)$ & 25.1 & $(14.7)$ \\
\hline AST (8-48 U/L) & 20.2 & $(5.5)$ & 20.1 & $(5.3)$ & 22.4 & $(6.3)$ & 23.3 & $(10.0)$ \\
\hline GGT (6-48 U/L) & 19.1 & $(11.7)$ & 19.9 & $(11.9)$ & 23.1 & $(13.4)$ & 24.7 & $(14.0)$ \\
\hline \multicolumn{9}{|l|}{ Kidney function } \\
\hline Urea $(15-46$ mg/dL) & 35.4 & $(9.1)$ & 33.0 & $(7.7)$ & 31.9 & $(7.8)$ & 30.1 & $(7.4)$ \\
\hline Creatinine $(0.6-1.3 \mathrm{mg} / \mathrm{dL})$ & 0.79 & $(0.18)$ & 0.74 * & $(0.16)$ & 0.74 & $(0.15)$ & 0.76 & $(0.16)$ \\
\hline $\mathrm{Na}(135-145 \mathrm{mmol} / \mathrm{L})$ & 141.2 & $(1.2)$ & 141.2 & $(2.1)$ & 141.7 & $(1.7)$ & 141.1 & $(1.7)$ \\
\hline $\mathrm{K}(3.6-5.2 \mathrm{mmol} / \mathrm{L})$ & 4.3 & $(0.3)$ & 4.3 & $(0.2)$ & 4.3 & $(0.2)$ & 4.3 & $(0.3)$ \\
\hline Heart rate $(\mathrm{bpm})$ & 71.8 & $(10.2)$ & 72.1 & (8.6) & 71.3 & $(11.2)$ & 70.4 & (16.4) \\
\hline
\end{tabular}

*-An intragroup difference between baseline (W1) and end of the study $\left(\mathrm{W}_{16}\right)$ at $p \leq 0.05$.

\section{Discussion}

The main results of this study demonstrate that a 16-week-long supplementation period with an ingredient formulated from a blend of various botanical extracts, which are rich in a diversity of polyphenols and usually consumed as part of the typical Mediterranean diet, is associated with significant improvements of both the physical and mental components of the HRQOL in overweight and obese but otherwise healthy subjects of both sex.

At baseline, volunteers showed an impaired HRQOL, namely in vitality and emotional well-being subscales, for which values were below the Spanish age-specific population reference norms [33]. Although similar studies have previously reported impairment across all off the SF-36 subscales, most of them were conducted either with a population displaying a significantly higher grade of obesity or with an additional manifestation of comorbidities [10,17]. Here, baseline impairments observed for vitality and emotional well-being are in line with the work of Blissmer et al. [11], who found similar decrements in a highly comparable population of healthy overweight and moderately obese subjects, indicating higher feelings of tiredness and anxiety.

Following a 16 week intervention period associated with a normal caloric diet, both the physical and mental components of the HRQOL significantly improved in volunteers supplemented with the polyphenol-rich ingredient compared to the placebo group. Net improvements were shown by subjective ameliorations in bodily pain $>$ general health $>$ vitality $>$ physical functioning $>$ emotional well-being. It is noteworthy that after the 16-week-long period of supplementation, both the vitality and the emotional well-being values improved to achieve the level of the reference norms of the Spanish age-specific population. Improvements in these different subscales and in both the physical and mental component scores must be considered as clinically significant, as it has been stated that absolute differences of 3-5 points are clinically relevant [34].

In addition to these improvements, the 16 week chronic polyphenolic supplementation induced significant body weight loss, with an average difference between both groups of $1.1 \mathrm{~kg}$. It is noteworthy that this decrease was essentially driven by an $86 \%$ fat mass reduction, for which $89 \%$ was located within the trunk area, pointing out a particularly beneficial effect on body composition. Such an improvement may, to some extent, positively impact the HRQOL. Indeed, some authors have demonstrated that weight loss was associated with improvement of both physical and mental health dimensions in several intervention trials [11,13,35-37]. Moreover, the amount of weight loss and the level of HRQOL improvement may be directly interconnected $[37,38]$. Nevertheless, here we did not demonstrate a significant correlation between weight or fat loss and HRQOL improvement, hypothesizing that weight loss could be an indirect consequence of HRQOL improvement, as it has been recently demonstrated with a bi-directional relationship between both parameters [39]. 
Moreover, catechins from green tea have previously been demonstrated to have antiobesity effects [40] through various mechanisms of action, such as the inhibition of pancreatic lipase [41], as well as through the regulation of obesity-related genes and proteins [42]. However, it is important to highlight that these interventional studies used significantly higher amounts of green tea catechins, whereas in the current supplement it only corresponded to one cup of green tea daily. Moreover, caffeine content and flavanones from grapefruit extract could also potentiate the decrease in body fat mass, as enhanced lipolysis leading to decreases in body weight and fat mass has previously been demonstrated in overweight and obese subjects supplemented with such kinds of bioactive compounds [43]. Accordingly, as each of the bioactive components in the supplement are present at lower levels compared to efficient dosages from the literature, it could be assumed that the beneficial observations for the supplement should be attributed to the whole formulation.

In parallel to body composition improvement, the level of physical activity, as assessed through the IPAQ questionnaire, significantly intensified $(p=0.05)$ after 16 weeks of supplementation. Thus, while $69 \%$ of volunteers from the supplemented group maintained their usual level of physical activity, $25 \%$ moved into a higher category compared with the placebo population, for which only $9 \%$ of volunteers improved their level of physical activity. Contradictorily, at the same time, the supplemented group showed a decrease in daily steps as assessed with a pedometer, while no change was observed in the placebo population. This discrepancy may be explained by the fact that pedometers are not suitable for the measurement of certain types of physical activity, such as swimming, cycling, or heavy lifting, which are otherwise assessed through the IPAQ questionnaire, making these both subjective and objective measurements, two complementary tools in physical activity assessment. As volunteers were encouraged to maintain their usual physical activity level throughout the course of the study, it can be hypothesized that the significantly higher physically active lifestyle reported within the supplemented group is not the result of conditioned mental engagement only. Indeed, the increase of HRQOL, and namely of the feeling of increased vitality, may explain such a rise in physical activity. A recent review that aimed at examining the link between physical activity and HRQOL concluded that there is a consistent cross-sectional association between physical activity level and HRQOL, namely in the vitality and in the physical functioning domains, however the finding could not confirm a causal relationship, i.e., "higher HRQOL leading to a higher level of physical activity, or vice versa, or mutual influence" [44]. Nevertheless, the engagement in a more active lifestyle within the supplemented population may also have a positive effect on body composition improvement, as discussed above.

Besides positive effects on body composition and engagement in physical activity, it appears that phenolic compounds may induce, through other various mechanisms, observable effects in terms of HRQOL improvement. Accordingly, adherence to a Mediterranean dietary pattern, characterized by wide consumption of fruits and vegetables, cereals, fish, olive oil, and red wine, has been directly associated with better QOL in an analysis including more than 11,000 participants that belonged to the SUN (Seguimiento University of Navarra) cohort $[45,46]$. While several nutrients and micronutrients may contribute to this effect, phenolic compounds have been suggested to be the main mediators; a large cross-sectional study demonstrated a direct relationship between the antioxidant contents of the Mediterranean diet, including the flavonoid content, and HRQOL [25]. In addition, in another recent study including more than 13,000 women, higher flavonoid intake at midlife was associated with increased odds of healthy ageing, based on higher survival at older ages free of chronic diseases and maintenance of midlife HRQOL (as assessed by the SF-36 survey) [47]. Here, despite the studied population being Spanish and particularly prone to complying with the Mediterranean diet, the MDSS did not demonstrate any significant adherence to this pattern in either groups, for whom the consumption of fruits and vegetables, the main sources of flavonoids, was below the recommendations of the last updated version of the Mediterranean Diet Pyramid [48]. Thus, it can be hypothesized that a regular basic diet has no or only a minor impact on HRQOL, since there were no 
improvements within the placebo population, whereas the supplemented subjects that covered the gap of phenolic micronutrients significantly improved their HRQOL.

Bioactive compounds occurring in the supplement may positively impact physiological functions related to both physical and mental health status-mainly vascular inflammation, coagulation factors, and endothelial function [25], which are all described to be impaired during overweight and obesity [49]. The aptitude of certain phenolic compounds in improving vascular health has been demonstrated both in vitro and in vivo [50]. Catechins from green tea positively impact vascular function through various complementary mechanisms linked to their antioxidative and anti-inflammatory properties, as well as to their capacity to activate endothelial NO synthase [51]. Similarly, grape polyphenols also demonstrated an aptitude to improving vascular impairments through similar molecular mechanisms [52], all contributing to a better peripheral and central blood flow, which in turn may positively affect physical and mental health status [53].

While modulation of both oxidative stress and inflammatory parameters, the main contributors in the improvement of vascular function and blood flow, has previously been demonstrated with the current supplement in a study involving obese subjects [32], specific mechanisms of flow-mediated dilation improvements and subsequent blood flow increase have not yet been investigated. Moreover, as the beneficial effect of the supplement on HRQOL has been demonstrated, further investigations will have to be conducted in attempts to confirm the causal relationship between the bioavailability and pharmacokinetics of the polyphenols metabolites and the mechanisms involved in improving vascular function.

Beyond the mentioned limitations, the results of the present study reveal the beneficial and systemic effects of phenolic compounds on subjective physical and mental symptoms linked to overweight and obesity. The study was designed to minimize bias, and thus individualized calorie intake recommendations and diet interviews, as well as monitoring of daily steps, were identified as possible confounding factors. Despite the studied population being recruited in a Mediterranean region, neither of the two groups adhered to the typical regional diet, which strengthens the hypothesis that phenolic compounds certainly contribute to subjective health, as previously proposed by others $[25,47]$.

In conclusion, this study demonstrated that the 16-week-long consumption of an ingredient obtained from polyphenol-rich fruit and vegetable extracts associated with both caffein and vitamin B3 supports improvements in HRQOL, specifically in both mental and physical subjective feelings. In addition, the decrease in body fat mass and the significantly increased engagement in physical activity probably established a virtuous cycle between body composition, physical activity, and perceived HRQOL. The mechanisms of action likely involve improvements in vascular function via well-known antioxidative and antiinflammatory properties of phenolic compounds. Such beneficial effects may be extended to other situations where HRQOL is impaired, particularly during the ageing process, where an imbalance of body composition and a loss of vitality and of physical functioning associated with a more sedentary lifestyle are commonly observed.

Author Contributions: Conceptualization, C.R. and J.C.; methodology, P.E.A. and L.H.C.; investigation, P.E.A., L.H.C., J.A.R.-A., E.M.-C., J.M.M.-R., and A.M.-R.; writing-original draft preparation, C.R.; writing-review and editing, C.R., J.C., P.E.A., L.H.C., J.A.R.-A., E.M.-C., J.M.M.-R., A.M.-R., S.G. and C.L. All authors have read and agreed to the published version of the manuscript.

Funding: This research received no external funding.

Institutional Review Board Statement: The study was conducted according to the guidelines of the Declaration of Helsinki, and approved by the Institutional Review Board of Comite de etica de la UCAM (protocol code $\mathrm{N}^{\circ} 5551$ on 24 April 2015).

Informed Consent Statement: Informed consent was obtained from all subjects involved in the study.

Data Availability Statement: The data presented in this study are available on request from the corresponding author, due to privacy restriction. 
Conflicts of Interest: Fytexia is involved in the research and development and marketing and sales of polyphenol extract-based ingredients for food and nutraceutical industries. Therefore, Fytexia has a commercial interest in this publication. UCAM and UMR 204 Nutripass were paid by Fytexia to perform and report the scientific work that formed the basis of this publication. Fytexia, UCAM, UMR 204 Nutripass, and all authors declare that the data in this report represent a true and faithful representation of the work that has been performed. The financial assistance of Fytexia is gratefully acknowledged.

\section{References}

1. Whoqol Group. The World Health Organization Quality of Life assessment (WHOQOL): Position paper from the World Health Organization. Soc. Sci. Med. 1995, 41, 1403-1409. [CrossRef]

2. Testa, M.; Simonson, D. Current concepts: Assessment of quality-of-life outcomes. N. Eng. J. Med. 1996, 334, 835-840. [CrossRef]

3. Fayers, P.M.; Machin, D. Quality of Life: Assessment, Analysis and Interpretation; John Wiley and Sons: Chichester, UK, 2000.

4. WHO. Noncommunicable diseases. World Health Organization. Available online: http://www.who.int/mediacentre/factsheets/ fs355/en/ (accessed on 7 March 2018).

5. Gortmaker, S.L.; Swinburn, B.A.; Levy, D.; Carter, R.; Mabry, P.L.; Finegood, D.T.; Huang, T.; Marsh, T.; Moodie, M.L. Changing the future of obesity: Science, policy, and action. Lancet 2011, 378, 838-847. [CrossRef]

6. Fernández-Sánchez, A.; Madrigal-Santillán, E.O.; Bautista, M.; Esquivel-Soto, J.; Morales-González, Á.; Esquivel-Chirino, C.; Durante-Montiel, I.; Sánchez-Rivera, G.; Valadez-Vega, C.; Morales-González, J.A. Inflammation, Oxidative Stress, and Obesity. Int. J. Mol. Sci. 2011, 12, 3117-3132. [CrossRef]

7. Rahman, I.; Bagchi, D. Inflammation, Advancing Age and Nutrition; Rahman, I., Bagchi, D., Eds.; Academic Press: London, UK, 2013.

8. Ahima, R.S. Connecting obesity, aging and diabetes. Nat. Med. 2009, 15, 996-997. [CrossRef]

9. Fontaine, K.R.; Barofsky, I. Obesity and health-related quality of life. Obes. Rev. 2001, 2, 173-182. [CrossRef] [PubMed]

10. Slagter, S.N.; Van Vliet-Ostaptchouk, J.V.; Van Beek, A.P.; Keers, J.C.; Lutgers, H.L.; Van Der Klauw, M.M.; Wolffenbuttel, B.H.R. Health-Related Quality of Life in Relation to Obesity Grade, Type 2 Diabetes, Metabolic Syndrome and Inflammation. PLoS ONE 2015, 10, 1-17. [CrossRef]

11. Blissmer, B.; Riebe, D.; Dye, G.; Ruggiero, L.; Greene, G.; Caldwell, M. Health-related quality of life following a clinical weight loss intervention among overweight and obese adults: Intervention and 24 month follow-up effects. Health Qual. Life Outcomes 2006, 4, 43. [CrossRef] [PubMed]

12. Ford, E.S.; Moriarty, D.G.; Zack, M.M.; Mokdad, A.H.; Chapman, D.P. Self-Reported Body Mass Index and Health-Related Quality of Life: Findings from the Behavioral Risk Factor Surveillance System. Obes. Res. 2001, 9, 21-31. [CrossRef] [PubMed]

13. Fine, J.T.; Colditz, G.A.; Coakley, E.H.; Moseley, G.; Manson, J.E.; Willett, W.C.; Kawachi, I. A Prospective Study of Weight Change and Health-Related Quality of Life in Women. JAMA 1999, 282, 2136-2142. [CrossRef] [PubMed]

14. Idler, E.L.; Benyamini, Y. Self-Rated Health and Mortality: A Review of Twenty-Seven Community Studies. J. Health Soc. Behav. 1997, 38, 21-37. [CrossRef] [PubMed]

15. Ware, J.E.; Snow, K.K.; Kosinski, M.; Gandek, B. SF-36 Health Survey Manual and Interpretation Guide; Health Institute, New England Medical Center: Boston, MA, USA, 1993.

16. Obidoa, C.; Reisine, S.; Cherniack, M. How does the SF 36 perform in healthy populations? A structured review of longitudinal studies. J. Soc. Behav. Health 2010, 4, 30-48.

17. Doll, H.A.; Petersen, S.E.K.; Stewart-Brown, S.L. Obesity and Physical and Emotional Well-Being: Associations between Body Mass Index, Chronic Illness, and the Physical and Mental Components of the SF-36 Questionnaire. Obes. Res. 2000, 8, 160-170. [CrossRef] [PubMed]

18. Marchesini, G.; Solaroli, E.; Baraldi, L.; Natale, S.; Migliorini, S.; Visani, F.; Forlani, G.; Melchionda, N. Health-related quality of life in obesity: The role of eating behaviour. Diabetes Nutr. Metab. 2000, 13, 156-164.

19. Caretto, A.; Lagattolla, V. Non-Communicable Diseases and Adherence to Mediterranean Diet. Endocrine, Metab. Immune Disord.-Drug Targets 2015, 15, 10-17. [CrossRef]

20. Tresserra-Rimbau, A.; Rimm, E.B.; Medina-Remón, A.; Martínez-González, M.A.; López-Sabater, M.C.; Covas, M.I.; Corella, D.; Salas-Salvadó, J.; Gómez-Gracia, E.; Lapetra, J.; et al. Polyphenol intake and mortality risk: A re-analysis of the PREDIMED trial. BMC Med. 2014, 12, 77. [CrossRef]

21. Crozier, A.; Jaganath, I.B.; Clifford, M.N. Dietary phenolics: Chemistry, bioavailability and effects on health. Nat. Prod. Rep. 2009, 26, 1001-1043. [CrossRef]

22. Boccellino, M.; D'Angelo, S. Anti-obesity effects of polyphenol intake: Current status and future possibilities. Int. J. Mol. Sci. 2020, 21, 5642. [CrossRef]

23. Castro-Barquero, S.; Lamuela-Raventós, R.M.; Doménech, M.; Estruch, R. Relationship between Mediterranean dietary polyphenol intake and obesity. Nutrients 2018, 10, 1523. [CrossRef]

24. Veronese, N.; Stubbs, B.; Noale, M.; Solmi, M.; Luchini, C.; Maggi, S. Adherence to the Mediterranean diett is associated with better quality of life: Data from the Osteoarthritis Initiative. Am. J. Clin. Nutr. 2016, 104, 1403-1409. [CrossRef] 
25. Bonaccio, M.; Di Castelnuovo, A.; Bonanni, A.; Costanzo, S.; De Lucia, F.; Pounis, G.; Zito, F.; Donati, M.B.; De Gaetano, G.; Iacoviello, L. Adherence to a Mediterranean diet is associated with a better health-related quality of life: A possible role of high dietary antioxidant content. BMJ Open 2013, 3, 1-11. [CrossRef] [PubMed]

26. World Health Organisation. Declaration of Helsinki World Medical Association Declaration of Helsinki Ethical Principles for Medical Research Involving Human Subjects. J. Am. Med. Assoc. 2013, 310, 2191-2194. [CrossRef] [PubMed]

27. Vijayananthan, A.; Nawawi, O. The importance of Good Clinical Practice guidelines and its role in clinical trials. Biomed. Imaging Interv. J. 2008, 4, e5. [CrossRef]

28. Roza, A.; Shizgal, H. The Harris Benedict energy requirements equation reevaluated: Resting and the body cell mass. Am. J. Clin. Nutr. 1984, 40, 168-182. [CrossRef] [PubMed]

29. Monteagudo, C.; Mariscal-Arcas, M.; Rivas, A.; Lorenzo-Tovar, M.L.; Tur, J.A.; Olea-Serrano, F. Proposal of a Mediterranean Diet Serving Score. PLoS ONE 2015, 10, e0128594. [CrossRef]

30. Vilagut, G.; Ferrer, M.; Rajmil, L.; Rebollo, P.; Permanyer-Miralda, G.; Quintana, J.M.; Santed, R.; Valderas, J.M.; Ribera, A.; Domingo-Salvany, A.; et al. The Spanish version of the Short Form 36 Health Survey: A decade of experience and new developments. Gac. Sanit. 2005, 19, 135-150. [CrossRef]

31. Craig, C.L.; Marshall, A.L.; Sjöström, M.; Bauman, A.E.; Booth, M.L.; Ainsworth, B.E.; Pratt, M.; Ekelund, U.; Yngve, A.; Sallis, J.F.; et al. International physical activity questionnaire: 12-Country reliability and validity. Med. Sci. Sports Exerc. 2003, 35, 1381-1395. [CrossRef]

32. Cases, J.; Romain, C.; Dallas, C.; Gerbi, A.; Cloarec, M. Regular consumption of Fiit-ns, a polyphenol extract from fruit and vegetables frequently consumed within the Mediterranean diet, improves metabolic ageing of obese volunteers: A randomized, double-blind, parallel trial. Int. J. Food Sci. Nutr. 2015, 66, 120-125. [CrossRef]

33. Alonso, J.; Regidor, E.; Barrio, G.; Prieto, L. Valores poblacionales de referencia de la versión española del Cuestionario de Salud SF 36. Med. Clin. 1998, 36, 1-10.

34. Samsa, G.; Edelman, D.; Rothman, M.L.; Williams, G.R.; Lipscomb, J.; Matchar, D. Determining clinically important differences in health status measures: A general approach with illustration to the Health Utilities Index Mark II. Pharmacoeconomics 1999, 15, 141-155. [CrossRef]

35. Rippe, J.M.; Price, J.M.; Hess, S.A.; Kline, G.; Demers, K.A.; Damitz, S.; Kreidieh, I.; Freedson, P. Improved psychological well-being, quality of life, and health practices in moderately overweight women participating in a 12-week structured weight loss program. Obes. Res. 1998, 6, 208-218. [CrossRef] [PubMed]

36. Kolotkin, R.L.; Fujioka, K.; Wolden, M.L.; Brett, J.H.; Bjorner, J.B. Improvements in health-related quality of life with liraglutide $3.0 \mathrm{mg}$ compared with placebo in weight management. Clin. Obes. 2016, 6, 233-242. [CrossRef] [PubMed]

37. Ross, K.M.; Milsom, V.A.; Rickel, K.A.; DeBraganza, N.; Gibbons, L.M.; Murawski, M.E.; Perri, M.G. The contributions of weight loss and increased physical fitness to improvements in health-related quality of life. Eat. Behav. 2009, 10, 84-88. [CrossRef] [PubMed]

38. Samsa, G.P.; Kolotkin, R.L.; Williams, G.R.; Nguyen, M.H.; Mendel, C.M. Effect of moderate weight loss on health-related quality of life: An analysis of combined data from 4 randomized trials of sibutramine vs placebo. Am. J. Manag. Care 2001, 7, 875-883. [PubMed]

39. Cameron, A.J.; Magliano, D.; Dunstan, D.; Zimmet, P.; Hesketh, K.D.; Peeters, A.; E Shaw, J. A bi-directional relationship between obesity and health-related quality of life: Evidence from the longitudinal AusDiab study. Int. J. Obes. 2011, 36, 295-303. [CrossRef]

40. Suzuki, T.; Pervin, M.; Goto, S.; Isemura, M.; Nakamura, Y. Beneficial effects of tea and the green tea catechin epigallocatechin-3gallate on obesity. Molecules 2016, 21, 1305. [CrossRef] [PubMed]

41. Grove, K.A.; Sae-Tan, S.; Kennett, M.J.; Lambert, J.D. (-)-Epigallocatechin-3-gallate Inhibits Pancreatic Lipase and Reduces Body Weight Gain in High Fat-Fed Obese Mice. Obesity 2012, 20, 2311-2313. [CrossRef]

42. Yang, C.S.; Zhang, J.; Zhang, L.; Huang, J.; Wang, Y. Mechanisms of body weight reduction and metabolic syndrome alleviation by tea. Mol. Nutr. Food Res. 2016, 60, 160-174. [CrossRef]

43. Dallas, C.; Gerbi, A.; Elbez, Y.; Caillard, P.; Zamaria, N.; Cloarec, M. Clinical Study to Assess the Efficacy and Safety of a Citrus Polyphenolic Extract of Red Orange, Grapefruit, and Orange (Sinetrol-XPur) on Weight Management and Metabolic Parameters in Healthy Overweight Individuals. Phytother. Res. 2014, 28, 212-218. [CrossRef]

44. Bize, R.; Johnson, J.A.; Plotnikoff, R.C. Physical activity level and health-related quality of life in the general adult population: A systematic review. Prev. Med. 2007, 45, 401-415. [CrossRef]

45. Ruano-Rodríguez, C.; Henriquez, P. (Patricia); Martinez-Gonzalez, M. (Miguel Ángel); Bes-Rastrollo, M. (Maira); Ruiz-Canela, M. (Miguel); Sanchez-Villegas, A. (Almudena) Empirically Derived Dietary Patterns and Health-Related Quality of Life in the SUN Project. PLoS ONE 2013, 8, 1-10. [CrossRef]

46. Sánchez, P.H.; Ruano, C.; De Irala, J.; Ruizcanela, M.; A Martínez-González, M.; Sanchezvillegas, A. Adherence to the Mediterranean diet and quality of life in the SUN Project. Eur. J. Clin. Nutr. 2012, 66, 360-368. [CrossRef] [PubMed]

47. Samieri, C.; Sun, Q.; Townsend, M.K.; Rimm, E.B.; Grodstein, F. Dietary flavonoid intake at midlife and healthy aging in women. Am. J. Clin. Nutr. 2014, 100, 1489-1497. [CrossRef] [PubMed]

48. Bach-Faig, A.; Berry, E.M.; Lairon, D.; Reguant, J.; Trichopoulo, A.; Dernini, S.; Medina, F.; Battino, M.; Belahsen, R.; Miranda, G.; et al. Mediterranean diet pyramid today. Science and cultural updates. Public Health Nutr. 2011, 14, 2274-2284. [CrossRef] 
49. Perticone, F.; Ceravolo, R.; Candigliota, M.; Ventura, G.; Iacopino, S.; Sinopoli, F.; Mattioli, P.L. Obesity and body fat distribution induce endothelial dysfunction by oxidative stress: Protective effect of vitamin C. Diabetes 2001, 50, 159-165. [CrossRef]

50. De Pascual-Teresa, S.; Moreno, D.A.; García-Viguera, C. Flavanols and Anthocyanins in Cardiovascular Health: A Review of Current Evidence. Int. J. Mol. Sci. 2010, 11, 1679-1703. [CrossRef]

51. Moore, R.J.; Jackson, K.G.; Minihane, A.M. Green tea (Camellia sinensis) catechins and vascular function. Br. J. Nutr. 2009, 102, 1790-1802. [CrossRef]

52. Dohadwala, M.M.; A Vita, J. Grapes and Cardiovascular Disease. J. Nutr. 2009, 139, 1788S-1793S. [CrossRef]

53. Watson, R.R.; Preedy, V.R.; Zibadi, S. Polyphenols in Human Health and Disease; Elsevier: Sandiego, CA, USA, $2014 ;$ Volume 1. 